Full Length Article

\title{
Adaptive behaviours of attacking futsal teams to opposition defensive formations
}

\author{
B. Travassos ${ }^{\mathrm{a}, \mathrm{b}, *}$, J. Bourbousson $^{\mathrm{c}}$, P.T. Esteves ${ }^{\mathrm{b}, \mathrm{d}}$, R. Marcelino ${ }^{\mathrm{b}}$, M. Pacheco ${ }^{\mathrm{a}}$, K. Davids ${ }^{\mathrm{e}}$ \\ ${ }^{a}$ Department of Sport Sciences, University of Beira Interior, Covilhã, Portugal \\ ${ }^{\mathrm{b}}$ Research Centre in Sports Sciences, Health Sciences and Human Development, CIDESD, CreativeLab Research Community, Portugal \\ ' Sport Sciences Faculty, University of Nantes, France \\ d Polytechnic Institute of Guarda, Guarda, Portugal \\ e Centre for Sports Engineering Research, Sheffield Hallam University, UK
}

\section{A R T I C L E I N F O}

\section{Article history:}

Received 27 November 2015

Revised 8 February 2016

Accepted 16 February 2016

Available online 23 February 2016

\section{Keywords:}

Team performance

Tactical behaviours

Futsal

Performance analysis

Defensive formation

Constraints

\begin{abstract}
A B S T R A C T
This study evaluated tendencies towards flexibility/stability of coordinated behaviours in international futsal teams, considered as complex collective systems, according to changes in opposition defensive formations. Six games of two international futsal teams (Spain and Portugal) were selected for Social Network Analysis to capture the coordination tendencies that emerge in the tactical behaviours of players when performing against different defensive formations. Ball trajectories in each offensive pattern of play were notated in an adjacency matrix where each entry accounted for the linkages between 12 spatial field areas. Each offensive play was coded according to the defensive formation of an opposing team (i.e. conservative or risky formation). Results revealed similar network properties between teams when competing against more risky defensive formations, while notable differences were observed against conservative defences. Effect of defensive formation of opponents on macro network properties was observed in both the Portuguese and Spanish teams. At a meso-level, only the Spanish national team exhibited notable changes, suggesting a greater level of adaptability to unfolding performance events. The observed flexibility in tactical behaviours of the Spanish team appeared to express their greater expertise levels. (c) 2016 Elsevier B.V. All rights reserved.
\end{abstract}

\section{Introduction}

Over the past few years, research on team sports performance has moved beyond the traditional notation of action frequencies and their relation to success, to consider the effects of situational game constraints on team performance (Lago \& Martín, 2007; Lago-Ballesteros, Lago-Peñas, \& Rey, 2012). For example, variations in some situational variables (e.g. game result, the on-field locale of ball recovery, or the balance in opposition teams) can constrain the attacking play exhibited by a team, resulting in changes in the probability of reaching the critical scoring space in football (Lago-Ballesteros et al., 2012). Also, in the team sport of Futsal, Gómez, Moral, and Lago-Peñas (2015) revealed that the probability of successfully maintaining ball possession depends on the type of team possession and the defensive formation of the opposition. These findings reinforce the idea that the adaptability of teams to emergent game constraints is crucial to improve performance and achieve competitive successful outcomes.

\footnotetext{
* Corresponding author at: Sport Sciences Department, University of Beira Interior, Convento de Sto. António, 6201-001 Covilhã, Portugal.

E-mail address: bruno.travassos@ubi.pt (B. Travassos).
} 
Additionally, analysis of team performance has moved beyond the notation of action frequencies towards a theoretical interpretation of patterns of play as emergent coordination tendencies in teams considered as complex collective systems (Travassos, Davids, Araujo, \& Esteves, 2013). Indeed there have been increasing attempts to analyze and interpret the emergent coordination tendencies between players of interacting teams in adopting such a complex systems approach to understanding team sports performance (Carling, Wright, Nelson, \& Bradley, 2014). It has been proposed that intra- and inter-team patterns of coordination can reveal team tactical behaviours (Davids, Araújo, \& Shuttleworth, 2005; Kempe, Grunz, \& Memmert, 2015; Silva, Garganta, Araújo, Davids, \& Aguiar, 2013). This conceptual approach suggests that analysis of how two competing teams continuously interact to achieve their performance goals can provide important insights into the adaptability of players and teams to the dynamics of competitive performance environments (Araújo \& Davids, 2009; Davids, Araújo, Correia, \& Vilar, 2013).

Previous research on team sports using Social Network Analysis (SNA) (Bourbousson, R'Kiouak, \& Eccles, 2015; Clemente, Martins, Wong, Kalamaras, \& Mendes, 2015; Duch, Waitzman, \& Amaral, 2010; Fewell, Armbruster, Ingraham, Petersen, \& Waters, 2012; Passos et al., 2011) has provided a quantitative expression of the interactions (i.e., links) between players, or field areas based on analysis of ball passing actions). Generally, SNA has revealed that changes in tactical behaviours are associated with successful or unsuccessful outcomes, with changes in game contexts or due to the expertise levels of the competing teams. For example, Passos et al. (2011), studying water polo teams, observed distinctive intra-team coordination tendencies between players that differentiated between successful and unsuccessful performance outcomes. Similar results have been reported in investigations of sports teams by Grund (2012), Fewell et al. (2012), Peña and Touchette (2012) and Duch et al. (2010). Their studies revealed that networks with high 'density' centralization tendencies (i.e., high relational links between players), but low 'betweenness' centralization predispositions (i.e., low dependency of the network structure on a specific player and consequently high flexibility of players' involvement), were associated with successful performance outcomes. Network structures of successful sport teams were characterized by a higher level of shared coordination between players and lower dependency on the performance of a specific leader. Recently, Gama et al. (2014) and Clemente et al. (2015) went further by identifying key individual players within team tactical performance using SNA techniques.

However, it is important to note that the impact of specific performance constraints, related to the dynamics of competitive environments, such as opposition defensive formations, on emergent coordination tendencies in sports teams still remains an open issue (Carling et al., 2014; Fewell et al., 2012; Gómez et al., 2015). Sport teams are constantly confronted with changes in performance environments during competition (i.e., co-positioning of opponent players, changes in ball location, game pace, match status) (Sampaio, Lago, Gonçalves, Maçãs, \& Leite, 2013), and their ability to rapidly adapt tactical behaviours is mandatory to achieving high performance levels (Eccles, 2010). For example, acknowledging levels of team flexibility (i.e., adaptation of patterns of play to a wider range of task solutions and styles of play according to changes in the competitive performance environment) or stability (i.e., maintaining a playing system yielding a limited range of task solutions or patterns of play, despite changes in the competitive performance environment) may reveal the potential for adaption to ever-changing situational performance constraints (Folgado, Lemmink, Frencken, \& Sampaio, 2012; Olthof, Frencken, \& Lemmink, 2015). As previously noted, team flexibility and a low reliance on the performance of a specific (superstar) player or a particular pattern of play, appear to be a hallmark characteristic of successful sport teams (Fewell et al., 2012; Grund, 2012). Thus, more research is needed to understand how, for example, changes in opposition defensive formation such as level of pressure exerted on the ball, may constrain the amount of ball possession and coordination tendencies that sustain successful team tactical behaviours in terms of stability and flexibility (Fewell et al., 2012; Gómez et al., 2015).

This study sought to characterize the coordination tendencies that sustain tactical behaviours of attacking teams according to changes in the opposition defensive formations in international futsal matches. Assuming that situational performance constraints such as the evolving spatial and temporal relations between players and teams are crucial to the emergence of team tactical behaviours, we analyzed how changes in the spatial formation of a defensive team (risky or conservative formation) impacted on the functions of an attacking team. We hypothesized that changes in defensive formations would differently influence the coordination tendencies (both at macro and meso-levels of organization) of attacking teams, providing insights into the variations in their tactical behaviours. Based on previous research (Duch et al., 2010; Grund, 2012; Peña \& Touchette, 2012), we also hypothesized that flexibility/stability levels of attacking teams would be related to their level of expertise. It was expected that the best-ranked international teams would express higher levels of flexibility in their coordination tendencies at different levels of organization according to changes in the defensive formation of their opponents.

\section{Methods}

\subsection{Participants}

The performance behaviours of two national teams which participated in the UEFA futsal Euro 2012 competition, Spain (Winner) and Portugal (5th ranked), were analyzed during four games at the group stage and two games in the knock out phase (from the quarter finals onwards). Three games of each team were considered for comparison purposes. The Portuguese and Spanish teams were selected for convenience according to the purposes of the study. The Spanish team was the overall winner of the competition and ranked first in the FIFA futsal rankings, while the Portuguese team came 
5th in the competition and was ranked seventh in the FIFA futsal rankings. This study was approved by the Ethics Committee of the CIDESD - Research Centre for Sports Sciences, Health and Human Development, Vila Real, Portugal.

\subsection{Data collection}

Offensive patterns of play were selected for analysis, based on two specific criteria: (i) starting with the recovery of ball possession in the defensive middle field, and (ii), ending with a shot at goal preceded by at least three passes without interception by an opponent (75\% of all the offensive sequences that ended with a shot at goal). The first criteria allowed us to better consider the effect of all defensive strategic positions on tactical behaviours of the team in possession of the ball, especially if the defenders where positioned near defensive line 1 . The second criteria permitted us to exclude counter-attacks from our analysis, as we were only interested here in analysing the dominant style of play recurrently used by both teams.

In accordance with these criteria, from a total of 70 offensive plays by Spain and 57 for Portugal, a random selection of a total of 114 offensive plays ( 57 for Spain, and 57 for Portugal) were visually extracted, ensuring a balanced sample. Ball trajectory of each offensive play was registered in a matrix where each entry accounted for the linkages between 12 spatial field areas (see Fig. 1) considered as nodes (Passos et al., 2011). According to the direction of the attack of the Portuguese or Spanish team, the 12 spatial field areas and the defensive lines were considered in a mirror fashion (see Fig. 1). This analysis considered the field areas as nodes and the passes or dribbles as links, with the same weight, expressing linkages between nodes. The specific court area in which performance actions (i.e., pass or dribble) occurred was not recorded, maintaining a similar level of analysis between passes and dribbles.

Each offensive play was also coded according to the defensive formation of the opposing team on field as: i) risky defense - when at least one opponent player was positioned ahead of opponent defensive line 1 (areas 1,2 or 3) and two additional opponents positioned between defensive line 1 and 2 (areas 4, 5 and 6) (Spain: $n=30$, Portugal: $n=34$ ), and ii), conservative defense - when at least one opponent player was positioned between opponent defensive lines 1 and 2 and the remaining behind defensive line 2 (Spain: $n=27$, Portugal: $n=23$ ) (see Fig. 1). The criteria for the identification of the type of defensive formation used by teams was based on coaching manuals and were identified by three expert futsal coaches $(M=13.6$, $s=2.49$ years of practice as futsal coaches). All coaches clearly expressed the view that the information they used to understand the defensive formation on field was based on the position of defensive players in relation to the defensive lines defined in coaching manuals (Jiménez \& Molina, 2006).

\subsection{Data analysis}

After data collection, ball trajectory data were reduced to identify and characterize linkages between field areas through a weighted digraph for each offensive sequence using SNA. Network properties of each offensive play were evaluated considering two levels of organization: a) macro-level and b) meso-level (Wasserman \& Faust, 1994). At a macro level we measured: 1) the Density Index, representing the number of passes that structured the network; 2) Out-degree centralization, representing the amount of passes/dribbles from one field area to other field areas; 3 ) In-degree centralization, characterising the amount of passes/dribbles received by one field area from other field areas; 4) Betweenness centralization, capturing the distribution of passes between field areas and the dependency of network structure to a specific field location; and finally d), Closeness centralization, $t$ representing the number of passes/dribbles needed to link one field area to others.

At a meso-level of analysis, we calculated: i) the Reciprocity index, capturing a dyadic relation by considering the number of linkages between two different nodes, and ii), the Transitivity index, characterising a closure of a triangular relationship in the linkages from area 1 to area 2 and to area 3 and also the direct links from area 1 straight to area 3 . All network property

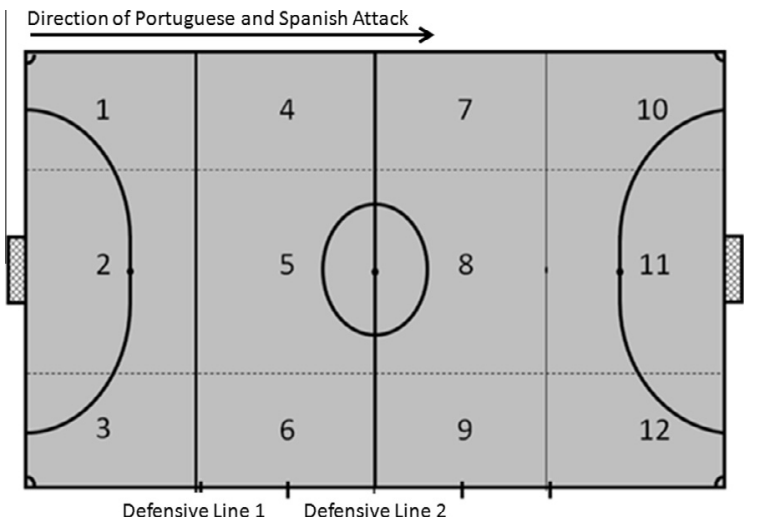

Fig. 1. Representation of futsal field divided in 12 field areas (1-6 in the defensive midfield and 7-12 in the offensive midfield). Defensive risky lines are also represented in the lower part: line 1: risky defensive formation; line 2: conservative defensive formation. 
analyses were conducted using *ORA software (CASOS, Carnegie Mellon) for each offensive pattern of play under consideration (for further information on the algorithms used see Bourbousson, R'Kiouak, and Eccles (2015)).

\subsection{Statistical procedures}

Data were analyzed for practical significance using magnitude-based inferences (Hopkins, Marshall, Batterham, \& Hanin, 2009). In line with our aims, we compared the network properties of each team (i.e., Spain and Portugal) when playing against different defensive situations (i.e., conservative vs. risky defensive formations). We also performed a betweenteam comparison to identify specific adaptations in view of the type of defensive formation adopted by the opposing team. Differences within the data sets were assessed via standardized mean differences computed with pooled variance, and respective 95\% Confidence Intervals (95\% CI) (Cumming, 2012). Magnitude thresholds for differences in a mean value were described using the following scale: $0-0.2$ trivial, $>0.2-0.6$ small, $>0.6-1.2$ moderate, $>1.2-2.0$ large, and $>2.0$ very large (Hopkins et al., 2009). To further elucidate the standardized mean differences and the power of the result, we computed the Common Language Effect Size statistic (CLES). CLES expresses the probability that a randomly selected score from one population will be greater than a randomly sampled score from another population (Cooper, Hedges, \& Valentine, 2009). All statistical computations were performed in RStudio (version 0.98.977) using the Package compute.es (version 0.2-3).

\subsection{Reliability}

From the six games, two of them were selected at random and analyzed by the first and the fifth authors. In order to assess inter-observer reliability, the minimum Cohen's K value was measured. Inter-observer reliability results were very good (values greater than .82) (O’Donoghue, 2009).

\section{Results}

\subsection{Defensive formation constrain tactical behaviours of teams in offense}

Analysis of the Spanish team revealed moderate effects of opponent defensive formation on network properties, both at the macro and meso-level of analysis (see Fig. 2). At the macro-level, higher density values were observed when facing a conservative as opposed to a risky defensive formation (CLES $=73.7 \%$ ) (see left panel of Fig. 2). These results indicated that the number of passes performed between field locations was higher against conservative compared to risky defensive formations. Generally, the field location to which and from where more passes were made against both types of defensive formations was area 5, followed by areas 4 and 6 . Results for the remaining macro-level variables were somewhat unclear. The Spanish team, at the meso-level of analysis, revealed higher values of Transitivity and Reciprocity, with moderate differences, when facing a conservative defense as opposed to a risky defensive formation (CLES $=76 \%$ and $77.5 \%$, respectively) (see Table 1). Results indicated that reciprocal passing relations between two and three field areas were more frequently observed against conservative compared to risky defensive formations.

Analysis of the Portuguese team's performance revealed moderate effects of defensive formations on network properties, but only at a macro-level of analysis (see right panel of Fig. 2). At the macro-level, higher Betweenness and Closeness centralization values were observed when facing a conservative as opposed to a risky defensive formation (CLES $=77.5 \%$ and $73.8 \%$, respectively) (see right panel of Fig. 2). In terms of Betweenness, these results indicated a high dependency of the passing relations from certain field areas (area 5 followed by area 4), and also a greater stability of the network against
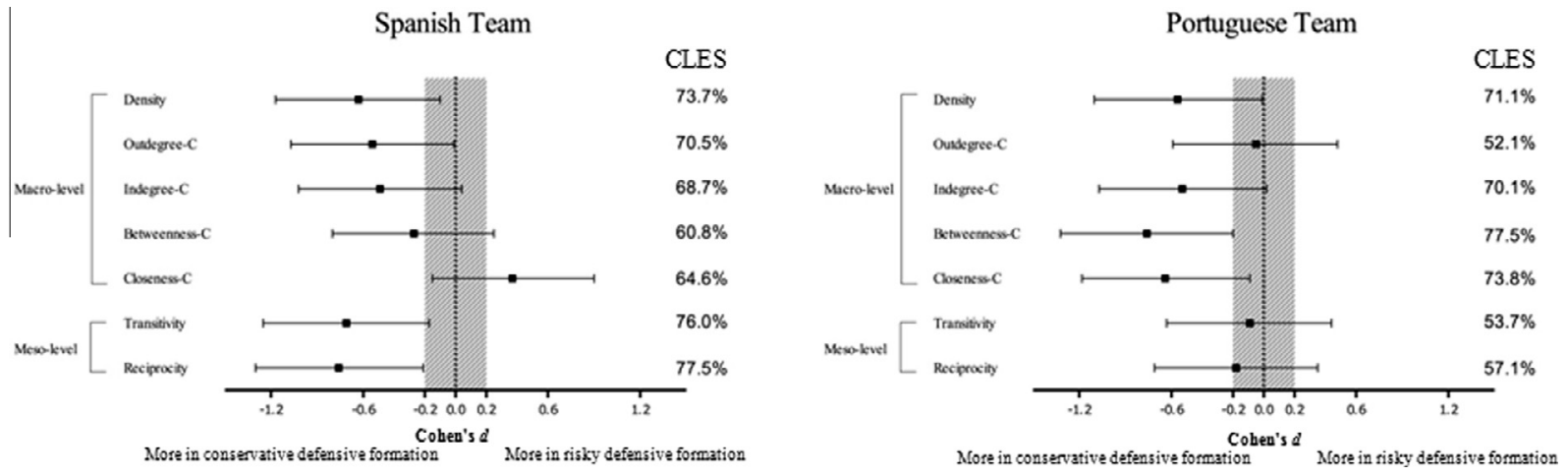

Fig. 2. Network properties in a macro and meso-level of analysis. Comparison of each team according to the type defense used by opponent team: Left Panel - Spanish team; Right Panel - Portuguese team. CLES = Common Language Effect Size. Error bars represent the 95\% confidence interval for the mean difference; shaded area = trivial effect size; 0.2, 0.6 and 1.2 represent the thresholds for small, moderate, and large effect sizes, respectively. 
Table 1

Results of SNA macro and meso-level of analysis for risky and conservative defensive formations for the teams of Portugal and Spain (dimensionless results).

\begin{tabular}{|c|c|c|c|c|c|c|c|c|c|}
\hline & & \multicolumn{4}{|c|}{ Portugal } & \multicolumn{4}{|l|}{ Spain } \\
\hline & & \multicolumn{2}{|c|}{ Risky $(n=34)$} & \multicolumn{2}{|c|}{$\begin{array}{l}\text { Conservative } \\
(\mathrm{n}=23)\end{array}$} & \multicolumn{2}{|c|}{ Risky (n = 29) } & \multicolumn{2}{|c|}{$\begin{array}{l}\text { Conservative } \\
(\mathrm{n}=28)\end{array}$} \\
\hline & & $M$ & $S D$ & $M$ & $S D$ & $M$ & $S D$ & $M$ & $S D$ \\
\hline \multirow[t]{5}{*}{ Macro-level } & Density & 0.034 & 0.020 & 0.046 & 0.025 & 0.037 & 0.022 & 0.054 & 0.032 \\
\hline & Out-degree-C & 0.099 & 0.038 & 0.101 & 0.047 & 0.096 & 0.039 & 0.121 & 0.053 \\
\hline & In-degree-C & 0.080 & 0.026 & 0.099 & 0.047 & 0.094 & 0.037 & 0.115 & 0.047 \\
\hline & Betweenness-C & 0.031 & 0.028 & 0.057 & 0.041 & 0.044 & 0.056 & 0.059 & 0.046 \\
\hline & Closeness-C & 0.051 & 0.020 & 0.066 & 0.028 & 0.054 & 0.021 & 0.047 & 0.019 \\
\hline \multirow[t]{2}{*}{ Meso-level } & Transitivity & 0.030 & 0.090 & 0.039 & 0.095 & 0.029 & 0.098 & 0.121 & 0.155 \\
\hline & Reciprocity & 0.081 & 0.126 & 0.108 & 0.175 & 0.099 & 0.154 & 0.239 & 0.209 \\
\hline
\end{tabular}

conservative compared to risky defensive formations. Closeness values expressed greater dispersion of ball passing trajectories, increasing the proximity between field locations against conservative compared to risky defensive formations. Results for the remaining macro-level variables as well as for the meso-level variables were somewhat unclear (see Table 1).

\subsection{Team tactical adaptations according to variations in defensive formations}

Comparison of network properties between teams was not clear cut when both teams faced a risky defensive formation (see right panel of Fig. 3). When facing a conservative defense, moderate effects were observed between the teams at the macro-level of analysis (see left panel of Fig. 3). The Portuguese team presented higher Closeness centralization values than the Spanish, against a conservative defensive formation (CLES $=78.8 \%$ ). This result indicated that, when facing a conservative defensive formation, Portuguese team expressed greater dispersion of ball passing trajectories, increasing the proximity between field locations, than the Spanish team. Results for the remaining macro-level variables were somewhat unclear.

At the meso-level of analysis, the Spanish team presented higher values than the Portuguese team for Transitivity and Reciprocity, when facing a conservative defensive formation (CLES $=73.1 \%$ and $74.7 \%$, respectively). These results indicated that when facing a conservative defensive formation, the Spanish team exhibited greater reciprocity of passing relations between two and three field areas than did the Portuguese team.

\section{Discussion}

This study analyzed performance of sports teams as complex collective systems and sought to characterize the coordination tendencies that sustain tactical behaviours of two attacking teams according to changes in the defensive formation of opponents in international futsal matches. In line with our first hypothesis, the Spanish and Portuguese teams both revealed adaptations in attacking tactical behaviours as a result of changes in the defensive formation of opponents. Results revealed similar coordination tendencies within both teams against more risky defensive formations, while notable differences were observed in coordination tendencies against conservative defences. The Spanish team revealed moderate effects on coordination tendencies, both at a macro and meso-level of analysis, while the Portuguese team only displayed changes in network properties at a macro-level of analysis.
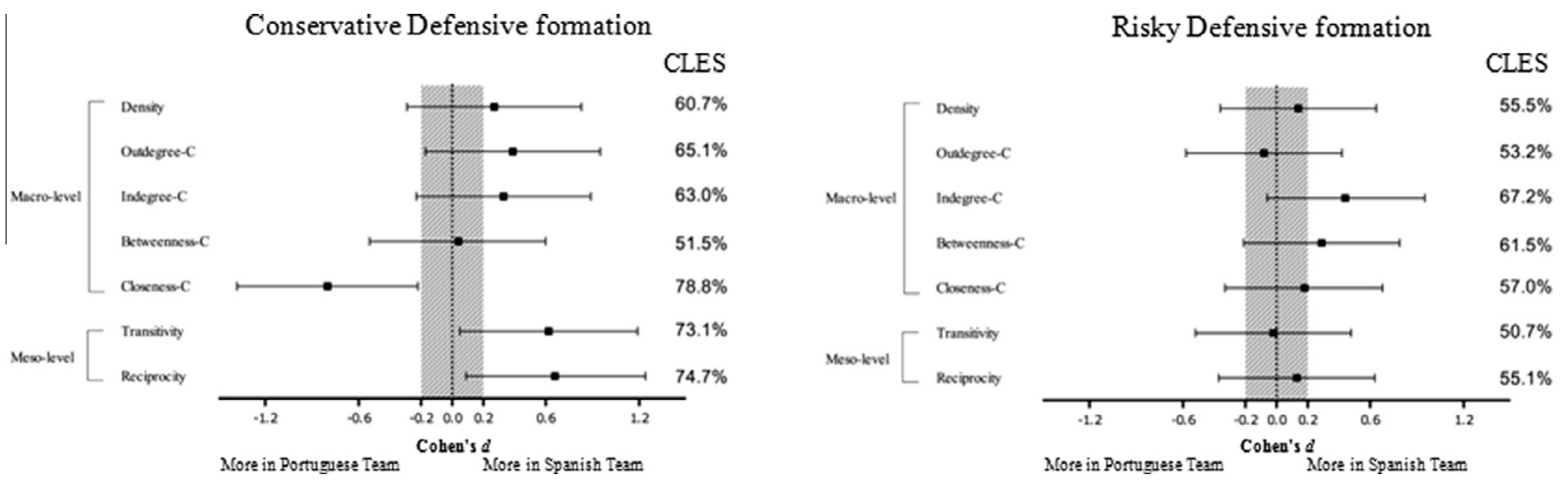

Fig. 3. Network properties in a macro and meso-level of analysis. Comparison of each type of defense used by opponent teams: Left Panel - conservative defensive formation; Right Panel - risky defensive formation. CLES = Common Language Effect Size. Error bars represent the 95\% confidence interval for the mean difference; shaded area = trivial effect size; 0.2, 0.6 and 1.2 represent the thresholds for small, moderate, and large effect sizes, respectively. 
The Spanish team exhibited a greater number of passes between field areas (i.e., higher Density values) when facing a more conservative defensive formation, compared to a risky defensive formation. This coordination tendency reflects a carefully-organised exploration of collective possibilities for passing all over the field (Duch et al., 2010; Grund, 2012; Peña \& Touchette, 2012), as opponents sought to reduce available space to play near their own goal. However, the court areas from where more passes were made and to which more passes were directed, were area 5 followed by areas 4 and 6 against both types of defensive formations. This finding implies that, despite the emergence of a greater number of passes between court areas when facing a more conservative defensive formation in comparison to a risky formation, the preferential field areas to explore collective possibilities for passing were similar.

The Spanish team also revealed a greater number of passing relations between players involving two and three field areas (i.e., dyads and triads of field areas) when the opposition adopted a more conservative, rather than risky, defensive formation. Again, with less available space to play, the Spanish team assembled more extensive triangular passing relations in proximal areas to the ball that favoured flexible solutions to move the ball towards the opposition goal (Peña \& Touchette, 2012). These results may be interpreted as signatures of collective system behaviour, eminently flexible at a local level to sustain a macro-level of organization.

Conversely, the Portuguese team showed distinctive coordination tendencies. A greater dependency on passing actions to particular field areas of play (areas 5 and 4) was observed against a more conservative defensive formation, contrasting with a greater passing distribution across all field areas when facing a risky defensive formation. These results were supported by an increase in Betweenness and Closeness centralization values. This tendency reflected a thorough exploration of the collective possibilities for passing by preferring a wider range of field areas for moving the ball from a specific field area ( 5 or 4 ) to when opponents sought to reduce available space to play near their own goal (Clemente et al., 2015; Duch et al., 2010; Grund, 2012; Peña \& Touchette, 2012). No differences were observed in network properties of the Portuguese team, at a meso-level of analysis, indicating stability at this level of organization (Yamamoto \& Yokoyama, 2011). This finding signifies that, with less available space to play, the Portuguese players' preferred invariant structures at a local level of interaction, despite the ongoing adaptations observed at macro-level. Given these results, the performance signature of Portuguese collective team behaviours may be synthesized by the creation of stability at local levels to sustain subsequent flexibility in passing distribution as opponents reduced available space to play near their own goal.

A between-team comparison interestingly showed relevant differences in network properties between the Portuguese and Spanish teams when the opposing team exhibited a conservative defense. This finding allows us to infer that, as the opposition reduced available space to play near their own goal, differences in tactical behaviours between the teams became more evident.

Thus, when faced with a conservative defense, the Portuguese team revealed, at a macro-level, higher values of Closeness centralization than the Spanish team. In practical terms, the Portuguese team exhibited greater variability in passing trajectories that expressed greater dispersion of ball on the field than the Spanish team. In contrast, at a meso-level, the Spanish team created more triangular passing relations in proximal areas to the location of the ball (i.e., to afford or invite more passing opportunities), compared to the Portuguese team. Thus, when facing a conservative defense, flexibility of local rules (meso-level) appeared to sustain coordination tendencies at a macro-level of organization of the Spanish team while the observed stability of local rules (meso-level) in the Portuguese team, seemed to support specific patterns of passing distribution.

The second hypothesis of our study was to ascertain whether teams' flexibility/stability in adapting to competitive environmental constraints could be related to their levels of expertise. There is some previous support for the relationship between superior levels of flexibility in coordination tendencies and level of expertise in team sports (Duch et al., 2010; Grund, 2012; Peña \& Touchette, 2012). In our study, the Spanish team showed greater flexibility in adapting to opposition defensive formations at both macro and meso-levels compared to the Portuguese team, which expressed greater stability at a local level. The observed flexibility of team coordination tendencies, across different levels of analysis, could be considered as a sign of greater expertise (Duch et al., 2010; Eccles, 2010; Grund, 2012). This interpretation was based on the findings of previous research, and because Spain won the European Tournament, whereas Portugal was ranked 5th, and also because Spain occupied 1st place in the FIFA futsal rankings and Portugal was 7th. The variability in coordination tendencies observed in the Spanish team were harmonious with the results attained in the tournament and highlighted their tactical adaptability to key impacting constraints, here the spatial formation of the opposition defense defensive (risky or conservative). According to previous research, the potential of players and sports teams to adapt tactical behaviours, on the basis of local rules that afford flexibility at the macro and meso-level of relations, is a distinctive performance asset to improve during practice (Araújo \& Davids, 2009; Eccles, 2010; Fewell et al., 2012; Sampaio et al., 2013). However, it is important to note that both tactical strategies under study were functional for attaining competitive performance goals, since all sequences of play resulted in the creation of effective shooting attempts by the attacking team. These results strengthen the idea that tactical behaviours of players and teams emerge through the exploitation of individual and collective possibilities for action, within a continuous information exchange between players, sustained by team-specific goals as intentional constraints that drive system behaviours (Davids et al., 2013; Silva et al., 2013).

\section{Conclusions}

The data reported here suggest how analysis of the distinctive strategies adopted by a sports team to adapt to the constraints of specific competitive performance environments can reveal their 'competitive identity signatures' (McGarry, 
Anderson, Wallace, Hughes, \& Franks, 2002). Of interest here was that the Spanish team revealed changes in network properties at both a macro and meso-level, while the Portuguese team only displayed differences at a macro-level of relations. Also, the main differences between teams were observed when opposing teams used a conservative defensive formation.

One limitation in this study that should be accounted for concerns the sample size. Future research should consider larger samples to pursue a greater generalization across different team sports which could provide further investigations of collective system performance at different performance levels (club, national and international). Despite the small sample used, this study stimulated new questions for the evaluation and characterization of tactical behaviours in sports teams. In line with the proposals of McGarry (2009) and Gómez et al. (2015), for tactical behaviours in team sports to be refined there is a need to consider the key situational constraints of competitive performance environments, such as variations in the defensive formation of opponent team.

This study provided some relevant practical implications for performance analysts, sport scientists and coaches: i) to improve the understanding of tactical behaviours, performance analysts and coaches should benefit from using a multilevel approach (Bourbousson, Deschamps, \& Travassos, 2014) that take account of team patterns of play, but also consider localised movements that sustain relations between players; ii) coaches and performance analysts should analyze tactical behaviours according to strategic changes during performance, such as variations in the opposition's defensive formations; iii) the 'competitive identity signatures' of each team appeared to be more clearly obvious when facing a conservative, rather than a risky defense; iv) the coaching process should be focused on promoting adaptability of team tactical behaviours according to a team strategy that confers an identity which, in turn, can be achieved by manipulating situational performance constraints such as defensive formations faced in training.

\section{Acknowledgment}

This research was developed with the support of the Portuguese Foundation for Science and Technology (UID/ DTP/04045/2013) and COMPETE 2020 (POCI-01-0145-FEDER-006969).

\section{References}

Araújo, D., \& Davids, K. (2009). Ecological approaches to cognition and action in sport and exercise: Ask not only what you do, but where you do it International Journal of Sport Psychology, 40(1), 5-37.

Bourbousson, J., Deschamps, T., \& Travassos, B. (2014). From players to teams: Towards a multi-level approach of game constraints in team sports. International Journal of Sports Science and Coaching, 9(6).

Bourbousson, J., R'Kiouak, M., \& Eccles, D. (2015). The dynamics of team coordination: A social network analysis as a window to shared awareness. European Journal of Work and Organizational Psychology. http://dx.doi.org/10.1080/1359432X.2014.1001977.

Carling, C., Wright, C., Nelson, L., \& Bradley, P. (2014). Comment on 'Performance analysis in football: A critical review and implications for future research'. Journal of Sports Sciences, 32(1), 2-7.

Clemente, F. M., Martins, F. M. L., Wong, D. P., Kalamaras, D., \& Mendes, R. S. (2015). Midfielder as the prominent participant in the building attack: A network analysis of national teams in FIFA World Cup 2014. International Journal of Performance Analysis in Sport, 15(2), 704-722.

Cooper, H., Hedges, L., \& Valentine, J. (2009). The handbook of research synthesis and meta-analysis (2nd ed.). New York: Russell Sage Foundation.

Cumming, G. (2012). Understanding the new statistics: Effect sizes, confidence intervals, and meta-analysis. New York: Routledge.

Davids, K., Araújo, D., Correia, V., \& Vilar, L. (2013). How small-sided and conditioned games enhance acquisition of movement and decision-making skills. Exercise and Sport Sciences Reviews, 41(3), 154-161.

Davids, K., Araújo, D., \& Shuttleworth, R. (2005). Applications of dynamical systems theory to football. In T. Reilly, J. Cabri, \& D. Araújo (Eds.), Science and football $V$ : The proceedings of the fifth world congress on sports science and football (pp. 537-550). Routledge.

Duch, J., Waitzman, J. S., \& Amaral, L. A. N. (2010). Quantifying the performance of individual players in a team activity. PLoS One, 5(6), e10937. http://dx.doi. org/10.1371/journalpone.0010937.

Eccles, D. (2010). The coordination of labour in sports teams. International Review of Sport and Exercise Psychology, 3(2), 154-170. http://dx.doi.org/10.1080/ 1750984 X.2010.519400.

Fewell, J. H., Armbruster, D., Ingraham, J., Petersen, A., \& Waters, J. S. (2012). Basketball teams as strategic networks. PLoS One, 7(11), e47445.

Folgado, H., Lemmink, K. A. P. M., Frencken, W., \& Sampaio, J. (2012). Length, width and centroid distance as measures of teams tactical performance in youth football. European Journal of Sport Science, 14(S1), S487-S492. http://dx.doi.org/10.1080/17461391.2012.730060.

Gama, J., Passos, P., Davids, K., Relvas, H., Ribeiro, J., Vaz, V., et al (2014). Network analysis and intra-team activity in attacking phases of professional football. International Journal of Performance Analysis in Sport, 14(3), 692-708.

Gómez, M.-Á., Moral, J., \& Lago-Peñas, C. (2015). Multivariate analysis of ball possessions effectiveness in elite futsal. Journal of Sports Sciences, 33(20), 2173-2181. http://dx.doi.org/10.1080/02640414.2015.1075168.

Grund, T. U. (2012). Network structure and team performance: The case of English premier league soccer teams. Social Networks, 34(4), 682-690.

Hopkins, W., Marshall, S., Batterham, A., \& Hanin, J. (2009). Progressive statistics for studies in sports medicine and exercise science. Medicine E Science in Sports E Exercise, 41(1), 3-12.

Jiménez, A. L. G., \& Molina, A. J. G. (2006). FúTBOL SALA. Táctica defensiva. Barcelona: Editorial Paidotribo.

Kempe, M., Grunz, A., \& Memmert, D. (2015). Detecting tactical patterns in basketball: Comparison of merge self-organising maps and dynamic controlled neural networks. European Journal of Sport Science, 15(4), 249-255.

Lago-Ballesteros, J., Lago-Peñas, C., \& Rey, E. (2012). The effect of playing tactics and situational variables on achieving score-box possessions in a professional soccer team. Journal of Sports Sciences, 30(14), 1455-1461.

Lago, C., \& Martín, R. (2007). Determinants of possession of the ball in soccer. Journal of Sports Sciences, 25(9), 969-974. http://dx.doi.org/10.1080/ 02640410600944626.

McGarry, T. (2009). Applied and theoretical perspectives of performance analysis in sport: Scientific issues and challenges. International Journal of Performance Analysis in Sport, 9(1), 128-140.

McGarry, T., Anderson, D. I., Wallace, S. A., Hughes, M. D., \& Franks, I. M. (2002). Sport competition as a dynamical self-organizing system. Journal of Sports Sciences, 20(10), 771-781. http://dx.doi.org/10.1080/026404102320675620.

O'Donoghue, P. (2009). Research methods for sports performance analysis. Routledge.

Olthof, S. B. H., Frencken, W. G. P., \& Lemmink, K. A. P. M. (2015). The older, the wider: On-field tactical behavior of elite-standard youth soccer players in small-sided games. Human Movement Science, 41, 92-102. http://dx.doi.org/10.1016/j.humov.2015.02.004. 
Passos, P., Davids, K., Araujo, D., Paz, N., Minguéns, J., \& Mendes, J. (2011). Networks as a novel tool for studying team ball sports as complex social systems. Journal of Science and Medicine in Sport, 14(2), 170-176. http://dx.doi.org/10.1016/j.jsams.2010.10.459.

Peña, J. L., \& Touchette, H. (2012). A network theory analysis of football strategies. . arXiv preprint arXiv:1206.6904.

Sampaio, J., Lago, C., Gonçalves, B., Maçãs, V. M., \& Leite, N. (2013). Effects of pacing, status and unbalance in time motion variables, heart rate and tactical behaviour when playing 5-a-side football small-sided games. Journal of Science and Medicine in Sport, 17(2), $229-233$.

Silva, P., Garganta, J., Araújo, D., Davids, K., \& Aguiar, P. (2013). Shared knowledge or shared affordances? Insights from an ecological dynamics approach to team coordination in sports. Sports Medicine, $1-8$.

Travassos, B., Davids, K., Araujo, D., \& Esteves, P. T. (2013). Performance analysis in team sports: Advances from an ecological dynamics approach. International Journal of Performance Analysis in Sport, 13(1), 83-95.

Wasserman, S., \& Faust, K. (1994). Social network analysis: Methods and applications. New York: Cambridge University Press.

Yamamoto, Y., \& Yokoyama, K. (2011). Common and unique network dynamics in football games. PLoS One, 6(12) e29638. 